\title{
¡La enseñanza de la Historia sin mujeres! Género, Currículum escolar y Libros de Texto: una relación problemática
} Teaching History Without Women! Gender,
School Curriculum and Textbooks: a
Problematic Relationship

\section{Aritza Saenz del Castillo Velasco}

Escuela Universitaria de Magisterio de Donostia Universidad del País Vasco-Euskal Herriko Unibertsitatea

\begin{abstract}
Resumen: El objetivo de este artículo será primeramente analizar desde una perspectiva de género el tratamiento dispensado por los libros de texto de historia de secundaria y bachiller a un periodo concreto de nuestro pasado más reciente, como fue el franquismo. Posteriormente y ante la ausencia de la visión de género en los contenidos y explicaciones históricas de estos manuales sobre el desarrollo social, entendiendo por tal la evolución, el cambio, la permanencia y la duración de la sociedad, sus estructuras y sus miembros, formularemos una propuesta didáctica dirigida a bachiller al objeto de descifrar la historia de las mujeres durante el franquismo.
\end{abstract}

Palabras clave: Enseñanza-Aprendizaje de Historia; Franquismo; Libros de Texto; Propuesta didáctica de Historia de género; Historia sin mujeres.

Abstract: The main objective of this article is to research the treatment of textbooks of history used in secondary schools from a gender point of view. To develop it, we are going to focus in a period of the recent history, as the Franco's dictatorship was. Later on and taking into account that gender's view is outside the contents and the explanations of the historic facts, which are close related to the development, the changes, the remains and the lasts of a society, its structures and its subjects, we are going to make a teaching proposal that allows the students to learn women's contribution during Franco's era.

Keywords: Teaching-Learning of History / Franco's dictatorship / Textbooks / Teaching proposal in Gender's history /History without women.

(Fecha de recepción: junio, 2014, y de aceptación: abril, 2015)

DOI: $10.7203 / \mathrm{DCES} .29 .3820$ 


\section{Introducción}

Dentro de la Didáctica de las Ciencias Sociales el análisis de los libros de texto empleados en la enseñanza-aprendizaje de la Historia es una corriente de análisis ya consolidada. Desde los más generalistas como el estudio emprendido por Merchán (2002), que examinaron la composición de los libros de texto y su relación con las metodologías empleadas por los educadores y con el comportamiento y estrategias de estudios de los educandos, hasta libros más específicos que analizan el tratamiento otorgado a un periodo histórico determinado, ahondando en el estudio crítico del diseño y desarrollo curricular a través de los diferentes aspectos que un libro aporta (contenidos, personajes, ilustraciones, ejercicios, metodologías-técnicas-estrategias de aprendizaje, subjetividad-objetividad en el léxico...) (Prats y Valls, 2011) han puesto de relieve la importancia de este material didáctico en el proceso de enseñanza -aprendizaje y como puede llegar a condicionar la construcción del conocimiento de los futuros ciudadanos que son nuestros educandos. Al fin y al cabo este saber conformará en el alumno una cosmovisión particular de la sociedad e influenciará sobremanera en su actuación y participación dentro de ella como ciudadano.

Como es sabido, el libro de texto es el material didáctico más recurrente en los procesos educativos y que pone al alcance del profesor y el alumno los contenidos que la mayoría social cree que es importante enseñar y aprender, siendo el resultado de una determinada "selección social de saberes culturales" y el vehículo a través del cual se deben alcanzar los objetivos marcados para la educación presentes en el currículum. Por consiguiente, el conocimiento que trasmiten y quieren reproducir en las futuras generaciones no es objetivo y guarda una estrecha relación con la ideología de los grupos sociales dominantes. Éstos, en su afán de consolidar su status quo, elegirán unos contenidos determinados que marcarán el conocimiento legítimo y socialmente funcional; por el contrario, aquellos contenidos que hagan referencia a otros grupos sociales y dejen entrever otro ordenamiento social, político, nacional, etc. serán postergados al ostracismo (Bourdieu, 1983). Como lo expresaría Agustín Escolano (1997): "el libro escolar es un espacio de memoria como espejo de la sociedad que lo produce, en cuanto que en él se representan valores, actitudes, estereotipos e ideología que caracterizan la mentalidad dominante, es decir, el imaginario colectivo que configura algunos aspectos fundamentales de lo que hoy se entiende por currículum oculto, y también del explícito. Textos e iconografía son un fiel reflejo del espiritu de un tiempo, de las imágenes de una sociedad".

Teniendo esto presente, el objetivo de este artículo será primeramente analizar desde una perspectiva de género el tratamiento dispensado por los libros de texto de historia de secundaria y bachiller a un periodo concreto de nuestro pasado más reciente, como fue el franquismo. Los análisis didácti- 
cos sobre esta etapa reciente de nuestra historia son novedosos y la mayoría de ellos centran su interés en el estudio de los contenidos y su carga ideológica (Mérida, 2011). Por el contrario, los análisis de género son escasos. Estudios más amplios sobre la naturaleza de este recurso didáctico han resaltado el carácter inamovible de los manuales de historia empleados en bachiller y E.S.O. frente a los cambios historiográficos incorporados recientemente al curriculum (Valls, 2007; Mainer, 1995). De este modo, los materiales didácticos por antonomasia siguen anclados en las tendencias positivistas, aunque van incorporando paulatinamente visiones más estructuralistas que centran su interés en los grandes procesos históricos. Como resultado, hoy en día la enseñanza-aprendizaje de la historia se centra principalmente en la descripción de las decisiones y acciones de los personajes políticos más relevantes, y en un segundo plano, en el análisis de la evolución económica, social y cultural, considerándolos el motor de los cambios sociales y por ende los únicos sujetos que transforman la historia.

La perspectiva de género en la ciencia histórica ha sido algo relativamente reciente, aunque contamos con abundante bibliografía al respecto (Scott, 1988; Rose, 2012). Cuando hablamos de historia de género e historia de las mujeres, y coincidiendo plenamente con la visión aportada por George Duby y Michelle Perrot (1991), rehuiremos del ejercicio de incorporar mujeres a título individual dentro de los relatos existentes sobre la historia, defecto de la historia más puramente positivista y carente de cualquier visión analítica e interpretativa, pues creemos que no ayudan en exceso a la comprensión de las realidades históricas. Por el contrario, el análisis de la interacción de hombres y mujeres en una sociedad determinada, puede ayudar a comprender mejor la causalidad de los diferentes ritmos y evoluciones que experimenta y las consecuencias que de ello se derivan, y que a la postre nos facilitará el entendimiento y la interpretación de la realidad social actual y en la que se insertan nuestros educandos, objetivo básico e irrenunciable de la enseñanza de la historia.

Esta tendencia dentro de la ciencia histórica ha tenido su correlato en el mundo educativo con la formulación de numerosas propuestas didácticas innovadoras que han incorporado a las mujeres como sujetos históricos dentro de la enseñanza y aprendizaje de la historia (Suárez y García Galán, 2014). Aun así, en los relatos de los libros de texto sigue prevaleciendo la visión androcéntrica tradicional. Una vez incorporada la Historia de Género al saber académico y disciplinar ${ }^{1}$, y también al currí-

${ }^{1}$ Sobre el periodo aquí estudiado, o séase, el franquismo, se dispone de abundante bibliografía que incorpora la visión de género en diferentes ámbitos de la sociedad. Valgan como ejemplos las obras de autoras como Gloria Nielfa (2003), Ángela Cenarro (2005) o R. Sánchez López (1990) entre otras. 
culum escolar de las Ciencias Sociales, su transposición didáctica todavía es un ejercicio que queda por hacer, pues los manuales de historia son un fiel reflejo de la historia positivista, que como veremos a continuación, centra su interés básicamente en la historia política, relegando a la historia de las mujeres y de género y también a la social a un segundo plano en el mejor de los casos, y en el peor, a su completa ausencia (González y Lomas, 2002; Santos Guerra, 2000; Gaudo, 1996). De este modo solamente adquieren relevancia momentos muy concretos de la historia de las mujeres, aquellos que pusieron en jaque el sistema de representación política y la desigualdad de derechos entre hombres y mujeres (los movimientos sufragistas, feministas). Sin embargo, su protagonismo en otros periodos de la historia es nulo. Según el estudio de López-Navajas (2014) el peso de las mujeres dentro de los libros de texto de ESO se sitúa alrededor del 8\%; en los estudios más favorables su presencia se eleva hasta el 16\% (Garreta y Careaga, 1986). Este déficit se ha ido subsanando lentamente incorporando mujeres al relato histórico, pero la perspectiva no ha cambiado. Siguen sin considerarlas sujetos históricos cuyas "actividades son significativas para la dinámica social, para la evolución de las sociedades en cualquiera de sus niveles"; además, no existe una continuidad en el relato (Fernández Valencia, 2005). Por ello nos enfrentamos a la "ablación de la memoria de las mujeres", pues éstas han vivido y experimentado diferentes realidades sociales, políticas, económicas o culturales a las aportadas por los relatos históricos presentes en estos manuales, y sus contribuciones a la generación del saber y del conocimiento han sido censuradas (Rodríguez, 2014; Espigado, 2004). Difícilmente se podrá alcanzar la comprensión global del devenir de las sociedades si dejamos a la mitad de sus sujetos fuera de la historia o simplemente las nombramos y las consideramos como algo complementario. Este proceder de los libros de texto contribuirá a la permanencia de arquetipos tradicionales de lo masculino y lo femenino que perpetúan la desigualdad de las mujeres en diferentes ámbitos de la vida (Blanco, 2000; Peñalver 2003).

En segundo lugar cabría la revisión de algunos conceptos empleados erróneamente en los manuales de historia, pues generalmente no tienen en cuenta la situación de las mujeres en un periodo histórico determinado. Términos como ciudadanos, sufragio universal, declaración de derechos, sociedad democrática, etc. que caracterizan la descripción de algunas sociedades históricas silencian tras de sí la merma de sus derechos civiles y políticos que padecen las mujeres (Sánchez, 2012). Esto nos conduce a unos desarrollos curriculares de las Ciencias Sociales completamente deficitarios, que difícilmente podrán alcanzar los principios educativos generales de no discriminación en función del sexo y de igualdad de oportunidades y los objetivos marcados para la enseñanza de esta área (Espigado, 2004).

Frente a este panorama y ante la ausencia de la visión de género en los 
contenidos y explicaciones históricas de estos manuales sobre el desarrollo social, entendiendo por tal la evolución, el cambio, la permanencia y la duración de la sociedad, sus estructuras y sus miembros y la interacción entre ambos, formularemos una propuesta didáctica dirigida a bachiller al objeto de descifrar la historia de las mujeres durante el franquismo. Frente a las metodologías memorísticas de aprendizaje tradicionales impulsadas en los libros de texto de historia, que afortunadamente poco a poco van cambiando, y que hacían del alumno un mero receptor de contenidos, impulsaremos metodologías más proactivas donde el alumno sea el propio protagonista de su aprendizaje, con la intención de que la enseñanza-aprendizaje se constituya en un proceso de interacción entre profesor y alumno, donde este último sea cada día más autónomo.

\section{Metodología y resultados}

El análisis de género sobre el tratamiento dispensado a la historia del franquismo por los libros de texto, se desarrollará mediante el examen de cuatro materiales didácticos empleados en la enseñanza secundaria en varios centros educativos del País Vasco durante el curso lectivo 20132014. Respecto a su naturaleza, 3 de los materiales empleados en la enseñanzaaprendizaje de la historia serán libros de texto, correspondientes a segundo de bachiller y cuarto de la E.S.O. Estos pertenecerán a los grupos editoriales con mayor tirada, como son Anaya y Santillana, en sus versiones publicadas para el País Vasco -que poco se diferencian de las del resto de comunidades si exceptuamos un apartado dedicado a la situación particular de cada territorio-, y otro que podría representar a las editoriales regionales como es Ostadar (García de Cortazar, 2009; Fernández Ros, 2013; Beobide, 2012). El que resta será un material didáctico elaborado por un profesor y empleado en la enseñanza de esta asignatura en segundo de bachiller.

En esta investigación seguiremos el esquema de análisis propuesto por Subirat y Tomé $(1992 ; 1993)$ para la detección del tratamiento diferenciado dispensado a uno y otro sexo en los libros de texto, donde centraremos nuestra atención en los siguientes campos:

a) Los personajes aludidos en los textos y en el lenguaje iconográfico

b) La importancia otorgada a las acciones realizadas por uno y otro sexo

c) Valores, comportamientos y actitudes atribuidos a cada sexo

d)Representación de la masculinidad y de la femineidad

e) Sexismo en el lenguaje - esta opción sólo podrá ser examinada en los manuales en castellano, pues los editados en euskara, por las propias características de esta lengua y su léxico, no hacen distinción entre sexos.

Respecto al primer punto, podemos afirmar que los principales protagonis- 
tas con nombre propio de la historia continúan siendo los hombres. Así, la presencia de personajes masculinos es aplastante en todos los libros de texto analizados. En el manual de la editorial Santillana, en la lección 14 dedicada al estudio de "La Dictadura de Franco (1939-1975)", de los 62 personajes aludidos, únicamente uno es mujer; en el libro de Anaya, "La dictadura de Franco (1939-1975)" (Frankoren diktadura 1939-1975) es tratada en su duodécima lección y en ella el comentario sobre mujeres se reduce a 4 frente a los 284 personajes masculinos referenciados. Nuevamente, en el manual de Ostadar, en su lección titulada "Gerraostea. Frankoren salbuespena” (Postguerra. La excepción de Franco), la presencia de mujeres queda reducida a la mínima expresión; así de los 32 personajes indicados sólo dos son mujeres. Respecto al material didáctico elaborado por el profesor de secundaria de un centro de enseñanza del País Vasco, observamos la misma dinámica seguida por los libros de texto, esto es, la completa ausencia de mujeres en el relato histórico, pues no constatamos la referencia a ningún personaje femenino, mientras las alusiones a personajes masculinos ascienden a 55 .

En esta línea, la representación de los puestos de responsabilidad en los materiales didácticos examinados es netamente masculina, pues fiel a la visión positivista, ésta recae en aquellos sujetos que ocupan la cúspide en la escala social. Éstos se erigen en el reflejo del devenir de la sociedad y su destino es equiparado irremediablemente al de toda la comunidad. Los dirigentes más destacados serán todos hombres, a excepción de Pilar Primo de Rivera, donde destacan Franco, Hitler, Mussolini, Eisenhower, Carrero Blanco, Arias Navarro, Juan Carlos de Borbón, etc.; en cuanto a la especificidad vasca figuraría José Antonio Aguirre. Mujeres como Mercedes Sanz Bachiller, Teresa Loring, Mónica Plaza, Mercedes Formica, Carmen Salinas, María Rosa Urraca Pastor, Lydia Falcón, etc. que fueron importantes en el devenir de la sociedad española durante el franquismo, y muy especialmente en los destinos de las mujeres, no tendrían cabida en estos relatos.

Ahondando en esta omisión de las mujeres en la historia, además de no aparecer en los puestos de poder o de responsabilidades políticas, éstas quedan completamente apeadas del grupo de nombres-hombres que componen el mundo de la cultura española del periodo franquista. De este modo, en los manuales analizados toda referencia al mundo de la cultura y sus nombres propios se escribe en masculino. Personajes como Ernesto Jiménez Caballero, José María Pemán, Dionisio Ridruejo, José Ortega y Gasset, Gabriel Celaya, Jorge Oteiza,... componen la intelectualidad española de este periodo. Incluso los textos o fuentes secundarias introducidas para profundizar en las explicaciones de los diferentes aspectos de la sociedad y su devenir corresponden todos a historiadores. No hay sitio para Carmen Laforet, Ana $\mathrm{M}^{\mathrm{a}}$ Matute, 
Carmen Martín Gaite, Mercé Rodoreda, María Zambrano, Pilar Narvión, Carmen Molinero... Sin quererlo pueden transmitir aquella vieja idea en boga durante buena parte del siglo XX, en donde el raciocinio era cosa de hombres, pues las mujeres al parecer no disponían de la capacidad cognitiva suficiente para dedicarse a las tareas del saber (Marañon, 1951; De la Granda, 1947).

Como se desprende de los datos precedentes, las mujeres continúan estando ausentes en los manuales de enseñanza de historia en pleno siglo XXI, y lo que aún es más importante, cuando aparecen, quedan completamente subordinadas a figuras masculinas o sus dotes de dirección y responsabilidad son silenciadas. Es el caso de Carmen Polo, esposa de Franco, única mujer que encontramos en el libro de la editorial Santillana. En Anaya obtenemos resultados análogos, pues de las 4 mujeres aparecidas, 2 son referencias a Carmen Polo y otra a Carmen Franco; como excepción tendríamos el caso de Pilar Careaga, que es nombrada junto a otros políticos monárquicos. Aun así, no se menciona que fue procuradora en las Cortes franquistas y alcaldesa de Bilbao, siendo la primera mujer en ocupar una alcaldía de capital de provincias por orden del Ministerio de Gobernación; tampoco destacan sus otras facetas, como ser la primera ingeniera industrial y maquinista de tren en España (Aguirrezkuenaga y Urkijo, 2008). En una línea completamente diferente a estos libros de texto, las dos referencias a mujeres que hace la editorial Ostadar se refieren a
Pilar Primo de Rivera, delegada nacional de la Sección Femenina de Falange y personaje de vital importancia durante todo el franquismo, pues fue la persona que más tiempo ostentó un cargo político bajo la dictadura; no obstante, este currículo es omitido.

Dejando a un lado el análisis de los personajes principales y con nombre propio, el estudio del protagonismo de cada sexo en los relatos de la historia se antoja clave a la hora de calibrar las prácticas sexistas de los libros de texto, pues facilitan la visualización de los valores, funciones y roles atribuidos a cada uno de ellos. Como podemos prever, la presencia de las mujeres dentro de las explicaciones de los acontecimientos y procesos históricos desarrollados durante este periodo es escasa. Así, en el manual de la editorial Santillana el protagonismo de las mujeres se reduce a explicaciones sucintas y sin ninguna continuidad, que sirven de complemento a explicaciones más generales. Como ejemplo tenemos los siguientes: en el desarrollo de la explicación sobre el descenso demográfico producido en la posguerra, aluden a la presencia de mujeres en el exilio (compartido con los hombres); dentro de la explicación sobre el organigrama totalitario y corporativo de tendencia falangista incorporado durante el primer franquismo, aparece una breve mención de la participación de las mujeres en la Sección Femenina de Falange y en las obras de asistencia social atribuidas a esta organización; en el apartado dedicado al desarrollo económico y a la moder- 
nización del país, se menciona la incorporación de las mujeres al mercado de trabajo en la década de los 60; por último, en los ejercicios propuestos al objeto de examinar la falta de libertades, la censura y la represión ejercida por el régimen franquista, aparece una breve mención sobre las normas de baño que deben respetar las mujeres (junto las normas propuestas para los hombres). Esta desconexión dificulta sobremanera la comprensión de la experiencia de las mujeres durante el franquismo.

En el libro de texto de Anaya únicamente encontramos dos notas que dejan entrever el protagonismo de las mujeres. Una de ellas hace referencia a la educación católica implantada en la "Nueva España", donde entre otros atributos, se subraya la enseñanza del "sometimiento de la mujer al varón". La otra corresponde a un pie de foto y se refiere a un grupo de mujeres suizas que se disponen a bañarse, donde se deja patente que la llegada del turismo provocó cambios ideológicos y culturales de calado en la sociedad española, en clara alusión a los trajes de baño menos recatados que portan estas mujeres, pero se silencia los esfuerzos realizados por las mujeres españolas en pos de cambiar su situación de subordinación.

En el manual de la editorial Ostadar el protagonismo de las mujeres está asociado a la idea de la domesticidad impuesta por el régimen y queda reflejado a través de dos textos. Uno corres- pondiente a un fragmento de un discurso pronunciado por Pilar Primo de Rivera en 1960 y otro correspondiente a un artículo publicado en la revista Teresa de la Sección Femenina en 1961. Considero de suma importancia estos dos textos insertos dentro del examen de la sociedad franquista, pues permiten realizar un análisis crítico de género y que el alumno-profesor vislumbre como desde el Estado y sus representantes se impulsó la idea de la domesticidad de las mujeres, con la subordinación que ello conllevaba.

Si analizamos la iconografía presente en estos manuales, la situación no cambia demasiado. En este examen centraremos nuestra atención en las representaciones humanas, ya que son las que más información pueden aportar en el análisis de género, y dejaremos a un lado las paisajísticas, cartográficas o objetuales (Burke, 2005). De las fotos e ilustraciones contenidas, la mayoría retratan a personajes masculinos con porcentajes en torno al 70\% (Santillana $74 \%$; Anaya 73\%; Ostadar 66\%)2. Más importante si cabe, es el significado que estos personajes representan y transmiten a través del lenguaje visual. Las imágenes presentes en el manual de Santillana enfatizan en la adscripción de las mujeres al entorno del hogar. Así 3 de las 5 fotografías contribuyen a reforzar el ideal de la domesticidad femenina, donde la representación social de las mujeres está ligada a la

\footnotetext{
${ }^{2}$ El material didáctico elaborado por el profesor de bachiller no contiene iconografía alguna.
} 
figura de esposas y madres y por ende a las responsabilidades de la familia y del hogar. Acordes con estos postulados, dos de las fotografías representan a mujeres en sus viviendas, una de ellas sirviendo la mesa y dando de comer a prole y la otra, preparando la comida en la cocina. Otra de las imágenes corresponde a la esposa de Franco, que adquiere relevancia por ser cónyuge del jefe del estado español. Por el contrario, tenemos dos imágenes relacionadas con la represión franquista que sitúan a las mujeres en la escena pública, rompiendo con esta ligazón de las mujeres al mundo privado del hogar. Una de ellas corresponde a una manifestación estudiantil disuelta por la policía, donde dos mujeres salen a la carrera. La que resta, representa a un grupo de mujeres republicanas represaliadas y públicamente señaladas a través del corte de pelo.

Las imágenes presentes en el libro de texto de Anaya y sus pies de fotos también contribuyen a la identificación de las mujeres con la domesticidad. Las instantáneas que describimos a continuación son un buen ejemplo: una de ellas retrata a un grupo de mujeres comprando pan; otras cuatro enfatizan en la idea de la maternidad femenina donde figuran una mujer de las barriadas de una ciudad cualquiera con un barreño a cuestas lavando a su hijo en un arrojo, otra capta a unas mujeres paseando a unos niños por el paseo de la Concha en San Sebastián, en otra aparece una mujer en un apeadero con un niño en su regazo, y por último, figura Carmen Polo a la vera del dictador
Franco con su hija Carmen Franco sentada sobre sus rodillas. Otra subraya los anhelos de las mujeres depositados en la formación de su nueva familia y hogar a través de la representación de unas mujeres observando unas maquetas de futuras viviendas a construir. Frente a esta representación de las mujeres vinculada al estrecho cerco del hogar y de lo privado, destacan dos fotografías que devuelven a las mujeres a la escena pública. En una de ellas tenemos una manifestación de adhesión a Franco liderada por la Sección Femenina de Falange, y otra protagonizada por mujeres suizas dispuestas a bañarse en una playa del litoral mediterráneo; aun así, esta última instantánea identifica a las mujeres como objetos sexuados a través de la representación de sus cuerpos (González y Lomas, 2002). Otras fotografías donde aparecen retratadas las mujeres son aquellas que hacen referencia a un grupo de ancianas en un asilo, a un par de mujeres segando en el pueblo alavés de Araya y a una asamblea universitaria de estudiantes. Resaltamos estas tres ilustraciones ya que sus pies de foto, tras el masculino genérico de la lengua castellana, esconden el rostro femenino de la pobreza y omiten la participación de las mujeres en las tareas del campo y en las protestas contra el régimen acaecidas en la educación superior (Blanco, 2003; Pérez, 2011).

En lo que al manual de Ostadar se refiere, las representaciones iconográficas de las mujeres están asociadas en buena parte a representaciones hogare- 
ñas o familiares. Así de las 5 ilustraciones donde se retratan personajes femeninos, una está en relación con las colas de racionamiento de Guipúzcoa, otra con Carmen Polo entrando bajo palio a una catedral y la última, con la representación de una escena familiar en torno a la televisión. De las dos restantes, una corresponde a un encuentro entre Pilar Primo de Rivera y destacadas mujeres del fascismo italiano, que deja en evidencia el protagonismo y la importancia de esta mujer en los destinos de las españolas; la otra, es una representación de una cabaretera en un cartel publicitario de la película de Luis García Berlanga Bienvenido Mister Marshall.

Profundizando en la no presencia de mujeres en las explicaciones históricas, en su representación como sujetos pasivos en la construcción de la historia y su soslayada adscripción a la parcela privada del hogar, en estos manuales de historia se constata la nula representación de las mujeres desarrollando distintas clases de trabajos. Toda mención a cualquier actividad económica se tiñe de masculino, donde nuevamente el masculino genérico ayuda a ocultar el protagonismo de las mujeres. De este modo, tenemos como portadores de actividad a los mineros, a los obreros y trabajadores en general, a los labradores o baserritarras, a los ganaderos de los caseríos, a los agricultores, a los trabajadores emigrantes, etc. La independencia económica de las mujeres brillaría por su ausencia y quedarían veladamente subordinadas a la actividad económica y laboral de los varones. Así se perpetúa el ideal del male bread winner family, donde los varones son identificados como los únicos proveedores de recursos en una familia. Un ejemplo muy gráfico es la explicación que el manual de Anaya aporta sobre lo mísero que son los sueldos de la mayor parte de la sociedad española durante el franquismo y su recurso a las horas extraordinarias, muy especialmente en los trabajadores asalariados, al objeto de equilibrar los presupuestos familiares (p. 374). Queda fuera de esta exposición el aporte económico que realizaron miles de mujeres a favor del sostenimiento económico de las familias que la historiografía ya ha demostrado hasta la saciedad (PérezFuentes, 2004; Babiano, 2007).

Relacionado con la nula representación de la actividad laboral de las mujeres hay que introducir una aclaración importante. Cuando entre las explicaciones aportadas por el libro de texto de Santillana sobre la modernización de España en la década de los 60, comenta la incorporación de las mujeres al mundo laboral (p. 291), hay que ahondar en el relato, pues puede llevar a equívoco y extender el pensamiento que hasta dicha fecha el trabajo extradoméstico de las mujeres era inexistente, aspecto fácilmente contrastable con manuales de historia al respecto, que evidencian la participación sempiterna de las mujeres jóvenes y solteras en los mercados de trabajo regulares (Borderías, 1993; Díaz, 2001). Conviene que se haga alusión al estado civil, pues es en definitiva a partir de la década de los 60 y más exactamente en la década 
de los 70, cuando las mujeres casadas comienzan a no abandonar la actividad laboral extradoméstica, lo que conllevará un incremento importante en la población activa y ocupada femenina. Por otra parte, no hay que desmerecer la economía de los cuidados y la principal aportación de las mujeres a las tareas reproductivas, que posibilitaron reducir las tasas de mortalidad y natalidad, rasgos de la modernización demográfica de un país (Durán, 1987).

Este reducido protagonismo de las mujeres en los libros de texto de historia analizados forma parte de su currículo oculto y responde a la imagen que se quiere transmitir de un grupo social determinado, como son las mujeres, silenciando su existencia y la participación de más de la mitad de la sociedad en las transformaciones históricas. Las reminiscencias del positivismo en la redacción de los libros de texto hace que las mujeres no tengan cabida, más si cabe en el estudio de un periodo como el franquista, marcadamente patriarcal, que pretendió reducir a las mujeres a la esfera privada y fuera de todo ámbito de poder y de protagonismo político, con contadas excepciones. Siguiendo esta línea, los libros de texto homogenizan la representación de las mujeres, adscribiéndolas a la esfera privada y asignándolas de forma subliminal y a través de un ejercicio de naturalización, las tareas del hogar y las funciones reproductoras, enmarcando su destino dentro de los roles de madres y esposas. De este modo, el relato que hallamos en los manuales no ayuda en la comprensión de la realidad social y muy especialmente en el entendimiento de la discriminación y situaciones vejatorias que padecieron las mujeres bajo el sistema patriarcal impuesto por la dictadura, si exceptuamos el libro de texto de Ostadar, y que valdrían para explicar y entender la permanencia de situaciones de desigualdad en nuestra sociedad. Este desconocimiento hará más complicado el avance hacia los objetivos de la educación actual en relación a políticas de igualdad entre ambos sexos, pues si no son detectadas y destacadas situaciones de discriminación, nuestros alumnos en primera instancia difícilmente podrán aprender a identificarlas, y en segundo lugar, a superarlas. Por ello, a continuación plantearemos las posibles líneas para el desarrollo de una propuesta didáctica que oriente el trabajo del alumno sobre una óptica de análisis e interpretación no andocéntrica de la realidad social, que pueda favorecer el principio de igualdad entre hombres y mujeres y recuperar del olvido el protagonismo de las mujeres en la composición de la sociedad y en su articulación (Alcázar, 2003). Este enfoque didáctico, además de centrar su atención en los contenidos conceptuales, también nos ayudará a trabajar los actitudinales relacionados en esencia con el estudio de las normas, los comportamientos y los valores sociales vigentes durante el franquismo, que posibilitarán la reflexión sobre el valor de la igualdad entre hombres y mujeres presente en el discurso aceptado mayo- 
ritariamente por numerosos agentes sociales hoy día.

\section{Un esbozo de propuesta didáctica sobre los modelos de género imperantes durante la dictadura franquista}

La justificación del diseño de una propuesta didáctica en este sentido la encontramos nada más introducirnos en el Diseño Curricular de la comunidad autónoma del País Vasco de 2010. Entre los objetivos generales del área de las Ciencias Sociales, Geografía e Historia y de las materias transversales como Educación para la Ciudadanía y los Derechos Humanos descritos por este documento para las etapas de la E.S.O. y bachiller, destacan aquellos que hacen referencia a la enseñanza y aprendizaje de los conceptos y valores aportados por la historia de género. Éstos son importantes, pues posibilitarán una intervención coeducativa más eficaz. Entre ellos destacan los siguientes:

- En las diferentes sociedades geográficas e históricas, estudiar y comprender los diversos quehaceres o funciones de las mujeres, así como sus máximos problemas, para emerger del silencio o el anonimato y constituirse como sujetos históricos.

- Valorar las aportaciones de las mujeres para el desarrollo de la historia

- Valorar la participación económica y social de las mujeres en todos los ámbitos y rechazar todas las formas de discriminación posibles.
- Identificar y analizar las causas y las consecuencias de la discriminación entre hombres y mujeres.

- Examinar el origen y la evolución histórica de la diferenciación sexual

-Impulsar actitudes y comportamientos tendentes a la igualdad de derechos entre hombres y mujeres, aun respetando las diferencias de cada sexo (iguales en la diferencia o diversidad)

-Propiciar una actitud crítica ante la discriminación y exclusión que experimentan las mujeres

-Potenciar actitudes críticas ante la violencia tanto física como psicológica contra las mujeres

Aparte de estos objetivos generales, para el tratamiento desde una perspectiva de género de los bloques temáticos referidos al periodo franquista presentes en el curriculum de $4^{\circ}$ de la ESO y de $2^{\circ}$ de bachiller que llevan por título "La dictadura de Franco" y "La dictadura de Franco. Exilio, represión y oposición" respectivamente, proponemos los siguientes objetivos que nos ayudarán en la consecución de los fines más generalistas arriba indicados (Botinas y Cabaleiro, 1996):

- Conocer y comprender la organización o la estructura social de la dictadura franquista, con sus cambios y permanencias.

- Examinar las relaciones sociales entre hombres y mujeres y como evolucionaron durante el mandato de Franco.

- Identificar la ideología patriarcal del régimen de Franco. 
- Saber interpretar las leyes y extraer de ellas las ideas principales y sintetizarlas.

- Identificar la relación existente entre las leyes y las actitudes y comportamientos impuestos a los diferentes grupos sociales.

- Identificar los diferentes roles sociales imputados a las mujeres y a los hombres a lo largo del franquismo.

- Comprender el significado de las actividades y espacios que ocupan las mujeres en función de los roles asignados.

- Conocer las resistencias protagonizadas por las mujeres frente a los modelos de género asignados y sus respuestas al objeto de cambiar su situación social.

En relación a los contenidos, esta guía de propuesta didáctica introducirá nuevos campos de enseñanza-aprendizaje, pues analizando el curriculum de E.S.O. y bachiller, observamos que pese a figurar entre los fines del área de las Ciencias Sociales rescatar del olvido la contribución de las mujeres a la historia y resaltar sus aportaciones, en la práctica ningún bloque de contenidos hace la más velada referencia, si exceptuamos el referido a la transición española que se inicia en 1975 y la alusión que hace al papel que juegan hombres y mujeres en los cambios históricos (Curriculum
E.S.O. p. 584) ${ }^{3}$. Por ello, propondremos nuevos contenidos que complementen la enseñanza-aprendizaje del periodo franquista y que presenten a las mujeres como sujetos activos de la historia, donde quede patente su contribución al devenir de la sociedad en sus permanencias, cambios y ritmos; por otro lado, prestaremos atención al análisis de los diferentes roles imputados a hombres y mujeres desde las esferas del poder, cómo fue su plasmación real en la vida cotidiana y qué modificaciones experimentaron estos modelos de género a lo largo de la larga dictadura.

Teniendo esto presente, en esta propuesta trabajaremos los siguientes contenidos. Entre los conceptuales destacarán el análisis de la legislación franquista en lo concerniente a las mujeres en su doble vertiente -civil y laboral-, que ilustrará a la perfección el modelo de mujeres impulsado desde las altas esferas del estado y su desarrollo a lo largo de casi 40 años. Seguidamente nos detendremos en el estudio de las manifestaciones de la vida cotidiana, profundizando en las tradiciones-costumbres y en las prácticas sociales vigentes durante el franquismo, donde sobresaldrá la visión de género aportada por la iglesia católica y la Sección Femenina de Falange; dentro de este apartado sugerimos el examen del mundo de la enseñanza y la supre-

\footnotetext{
${ }^{3} \mathrm{Al}$ examinar los textos históricos a comentar en la prueba de acceso a la universidad que los alumnos de segundo de bachiller deben encarar, nos encontramos con problemas análogos. Así de los 24 textos seleccionados en el País Vasco, únicamente uno de ellos hace referencia a la aportación de las mujeres a la historia y recalca la realidad social en que éstas se encontraban.
} 
sión de la coeducación y el impulso de la educación segregada o diferenciada por sexos, fiel reflejo de las funciones sociales a aprehender e imputadas a cada uno de ellos. De igual modo, prestaremos especial atención a la representación de hombres y mujeres en relación a la gestión de las esferas púbico-privadas en la vida cotidiana. Como último apartado, examinaremos otras realidades sociales que quedan al margen y contradicen el modelo de género propagado con insistencia desde la retórica franquista.

Creemos que es de vital importancia que el alumno en su proceso de aprendizaje perciba la historia como una auténtica ciencia, donde los conocimientos no se presentan de forma acabada y están abiertos a la experimentación, pues con ello despertaremos su inquietud y redoblaremos su motivación en el estudio. El alumno será el protagonista en la construcción del conocimiento. Por ello, le introduciremos en el proceder de la tarea investigadora, donde aprenderá a buscar información, a gestionarla, a tratarla, a interpretarla y finalmente a expresarla correctamente de forma oral o escrita. De este modo se acercará a las principales fuentes de información histórica y profundizará en sus características y en su explotación. De igual manera, en este proceso ahondará en el análisis de textos e iconografía, aprendiendo a detectar las ideas principales y a establecer entre ellas un orden de jerarquización; a su vez, potenciaremos el pensamiento crítico a través de la interpretación de los textos e imágenes.
Por último, entre los contenidos actitudinales aprenderán a valorar críticamente la diversidad, desde un punto de vista y un conjunto de valores apoyados en la igualdad de derechos y oportunidades, que facilitará la convivencia entre grupos sociales y humanos distintos. A su vez, a través del análisis de realidades históricas donde la segregación y la discriminación por razón de sexo está presente, profundizarán en los valores democráticos, en los comportamientos cívicos y en la convivencia pacífica y tolerante que esta sociedad hace suyos y quiere transmitir a las generaciones venideras.

\section{Conclusiones}

¿Cómo podemos llegar a comprender los principios democráticos e igualitarios entre hombres y mujeres vigentes en nuestra sociedad e impulsados decididamente desde el currículum escolar, sin hacer una reflexión crítica, ni tener en cuenta el camino recorrido para su aceptación? Creemos que el estudio histórico del periodo franquista, por su carácter antidemocrático y claramente patriarcal, amén de su proximidad cronológica, puede representar una buena opción para profundizar en el aprendizaje de estos contenidos actitudinales, a la vez que trabajamos los conceptuales y procedimentales. De este modo, detenernos en situaciones sociales de desigualdad, discriminación o segregación nos ayudarán a poner en valor los valores democráticos aceptados por nuestra sociedad. 
La enseñanza-aprendizaje de los valores no se puede fundamentar en metodologías memorísticas, estableciendo una división entre el bien y el mal que debe ser aceptada e interiorizada por el alumno. Es conveniente predicar con el ejemplo, y que el proceso educativo presente en las aulas elimine cualquier práctica discriminatoria por razón de sexo. El profesor debe aprender y enseñar a convivir con la diferencia y a combatir las desigualdades (Alcázar, 2003). Que mejor que empezar por los materiales didácticos más representativos y que dejen constancia de la contribución de las mujeres en la composición y desarrollo de las sociedades.

De lo observado hasta la fecha, creemos sinceramente que los contenidos elaborados por los libros de texto son insuficientes para perseverar adecuadamente en este objetivo. En primer lugar, las mujeres están completamente ausentes del relato histórico; en segundo lugar, no existe referencia alguna a su situación de subordinación, discriminación o segregación que pueda inducir a la reflexión personal sobre los valores; en tercer lugar, las mujeres son representadas, con contadas excepciones, como sujetos alejados de los puestos de responsabilidad y poco influyentes en los cambios sociales que precipitan los cambios históricos. Este currículum oculto de los manuales de historia lo considero inadecuado, pues puede llevar a que los alumnos, a través del conocimiento histórico, naturalicen el mito del patriarcado y entiendan a las mujeres como seres inferiores moral, intelectual y físicamente.

\section{Referencias bibliográficas}

AGIRREZKUENAGA, J., Y URQUIJO, M. (2008). Bilbao desde sus alcaldes: diccionario biográfico de los alcaldes de Bilbao y gestión municipal en la dictadura (1939-1979). Bilbao: Biblioteca Universitaria UPV-EHU.

ALCÁZAR CRUZ, M. (2003). Educación para la igualdad desde el ámbito de las Ciencias Sociales. Íber, $n^{\circ} 35$, 65-76.

BABIANO MORA, J. (coord.) (2007). Del hogar a la huelga. Trabajo, género y movimiento obrero durante el franquismo. Madrid: Libros de la Catarata.

BEOBIDE, H. et al. (2012). Ostadar Berria, Gizarte Zientziak, DBH 4. Donostia: Elkarlanean.

BLANCO, N. (2000). El sexismo en los materiales educativos de la E.S.O. Sevilla: Instituto Andaluz de la Mujer.

BORDERÍAS, C. (1993). Entre Líneas. Trabajo e identidad femenina en la España Contemporánea. La Cía. Telefónica 1924-1980. Barcelona: Icaria.

BOTINAS, E. Y CABALEIRO, J. (1996). Consideraciones sobre la historia de las mujeres. Íber, $\mathrm{n}^{\circ} 10,119-128$.

BOURDIEU, P. (1983). Sistemas de enseñanza y sistemas de pensamiento. En J. GIMENO y A. PÉREZ (eds.), La enseñanza: su teoría y su práctica (20-36). Madrid: Akal. 
BURKE, P. (2005). Visto y no visto. El uso de la imagen como documento histórico. Barcelona: Crítica.

CENARRO, A. (2005). La sonrisa de Falange. Auxilio Social en la guerra civil y en la posguerra. Barcelona: Crítica.

DE LA GRANDA, A. (1947). Los fundamentos biológicos del trabajo en la mujer. Revista del Trabajo, $\mathrm{n}^{\circ} 5$, 489-498.

DÍAZ SÁNCHEZ, P. (2001). El trabajo de las mujeres en el textil madrileño. Racionalización industrial y experiencias de género (1959-1986). Málaga: Atenea.

DUBY, G. Y PERROT, M. (1991). Historia de las mujeres. Madrid: Taurus.

DURÁN, M. A. (1987). De puertas adentro. Madrid: Instituto de la Mujer.

ESPIGADO, G. (2004). Historia y genealogía femenina a través de los libros de texto. En C. RODRIGUEZ (comp.), La ausencia de las mujeres en los contenidos escolares (113-145). Argentina: Niño y Dávila.

ESCOLANO, A. (1997), El libro escolar: perspectivas históricas. En L. ARRANZ MÁRQUEZ (coord.), $E l$ libro de texto. Materiales didácticos. Actas del $5^{\circ}$ Congreso. Tomo I (3750). Madrid: UCM.

FERNANDEZ ROS, J.M. ET AL. (2013). Espainiako Historia. 2. Batxilergoa. Etxebarri: Zubia-Santillana.

FERNÁNDEZ VALENCIA, A. (2005). Las mujeres como sujeto histórico: género y enseñanza de la historia.
Didáctica de las Ciencias Experimentales y Sociales, $\mathrm{n}^{\circ}$ 18, 5-24.

GARCÍA DE CORTAZAR, F. ET AL. (2009). $2^{\circ}$ de bachillerato. Historia. Madrid: Anaya-Haritza.

GARRETA, N. y CAREAGA, P. (1987). Modelos masculino y femenino en los textos de E.G.B. Madrid: Serie Estudios 14.

GAUDÓ, C. (1996). Mujeres para la historia. Íber, $\mathrm{n}^{\circ}$ 7, 61-71.

GONZÁLEZ, A. y LOMAS, C. (coord.) (2002). Mujer y educación. Educar para la igualdad, educar desde la diferencia. Barcelona: Graó.

LÓPEZ-NAVAJAS, A. (2014). Análisis de la ausencia de las mujeres en los manuales de la ESO: una genealogía de conocimiento ocultada. Revista de Educación, $\mathrm{n}^{\circ} 363$, 282-308. DOI: 10.4438/1988-592X-RE-2012-363-188.

MAINER, J. (1995). ¿Nuevos libros para reformar la enseñanza? Apuntes sobre los textos escolares de Ciencias Sociales para la Secundaria Obligatoria. Íber, $\mathrm{n}^{\circ} 4,87-103$.

MARAÑÓN, G. (1951). Ensayo sobre la vida sexual. Madrid: Espasa-Calpe.

MERCHÁN, F.J., (2002). El uso del libro de texto en la clase de Historia. Gerónimo de Uztariz, $\mathrm{n}^{\mathrm{o}}$ 17-18, 79-106.

MÉRIDA DONOSO, J.A., "Intentando no olvidar: Acerca de la didáctica de la dictadura franquista en clases de Cultura y civilización", no 232 , 15 de octubre de 2011, Recuperado de www.claseshistoria.com/revis - 
ta /2011 / articulos / merida-didactica-franquismo.pdf

NIELFA, G. (ed.) (2003). Mujeres y hombres en la España franquista: Sociedad, economía, política, cultura. Madrid: Editorial Complutense.

PEÑALVER, R. (2003). ¿Qué quieres enseñar? Un libro sexista oculta a la mitad. Murcia: Instituto de la Mujer.

PÉREZ, A. (2011). El sexismo en los manuales escolares de Ciencias Sociales de la E.S.O. Recuperado del Repositorio Institucional de la Universidad de Almería: http://repositorio.ual. es:8080/jspui/bitstream/10835/1142/1/ Perez_\%20Lopez_Alicia.pdf [8 de noviembre de 2014].

PÉREZ-FUENTES HERNÁNDEZ, P. (2004). Ganadores de Pan y Amas de Casa. Bilbao: Servicio Editorial de la Universidad del País Vasco.

PRATS, J. y VALLS, R. (2011). La Didáctica de la Historia en España: estado reciente de la cuestión. Didáctica de la Ciencias Experimentales y Sociales, $\mathrm{n}^{\circ} 25,17-35$.

RODRÍGUEZ MARTÍNEZ, C. (2014). La invisibilidad de las mujeres en los contenidos escolares. Cuadernos de Pedagogía, $\mathrm{n}^{\circ}$ 447, 32-35.

ROSE, S.(2012). ¿Qué es historia de género? Madrid: Alianza Editorial.

SÁNCHEZ, J. (2012). Las mujeres en los libros de texto escolares de historia: entre la exclusión y el (mal) disimulo. Recuperado de Achencia de Noticias de Aragón: http://arain- fo.org/2012/01/las-mujeres-en-loslibros-de-texto-escolares-de-historia-entre-la-exclusion-y-el-maldisimulo/ [1 de diciembre de 2014]

SÁNCHEZ LÓPEZ, R. (1990). Mujer española, una sombra de destino en lo universal. Trayectoria histórica de Sección Femenina de Falange (19341977). Murcia: Servicio de Publicaciones de la Universidad de Murcia.

SANTOS GUERRA, M.A. (coord.) (2000), El harén pedagógico. Perspectiva de género en la organización escolar. Barcelona: Graó.

SUÁREZ, C. Y GARCÍA GALÁN, S. (2015). La inclusión de la historia de las mujeres en el nuevo paradigma educativo de la historia. Análisis curricular y propuestas didácticas. Historia \& Ensino, ${ }^{\circ} 1,29-56$. DOI: 10.5433/2238-3018.

SCOTT, J. (1988). Gender and politics of History. New York: Columbia University Press.

SUBIRATS, M. y TOMÉ, A. (1992). Pautas de observación para el análisis del sexismo en el ámbito educativo. Barcelona: Institut de Ciènces de l'Educació, Universitat Autònoma de Barcelona.

SUBIRATS, M. (coord) (1993). El sexismo en los libros de texto: análisis y propuestas de indicadores. Madrid: Instituto de la Mujer.

VALLS, R. (2007). Historiografía escolar española: siglos XIX y XXI. Madrid: UNED. 
